\title{
The Ability of Different Nickel-Titanium Rotary Instruments to Induce Dentinal Micro-cracks during Root Canal Preparation
}

\author{
Jagat Bhushan ${ }^{1}$ Garima Gupta ${ }^{1}$ Abhisheik Gupta ${ }^{1}$ \\ ${ }^{1}$ Department of Conservative Dentistry and Endodontics, \\ Dr. Harvansh Singh Judge Institute of Dental Sciences and \\ Hospital, Panjab University, Chandigarh, India
}

\begin{abstract}
Address for correspondence Jagat Bhushan, MDS, Department of Conservative Dentistry and Endodontics, Dr. Harvansh Singh Judge Institute of Dental Sciences \& Hospital, Panjab University, Chandigarh 160014, India (e-mail: drjagat@gmail.com).
\end{abstract}

Dent J Adv Stud 2018;6:71-75

\begin{abstract}
Objective The aim of this study was to investigate the incidence of cracks in root dentin after root canal preparation with SmartTrack files, ProTaper Next files, and HyFlex CM files.

Materials and Methods Sixty extracted single-rooted human mandibular premolars with one canal were used for the study. Fifteen teeth were left unprepared and served as control; another 15 were instrumented with SmartTrack files up to 30/0.06, and the remaining 30 were shaped with ProTaper Next till X3 and HyFlex CM files up to $30 / 0.04$. After root canal preparation, all the roots were sectioned perpendicular to the long axis at 2, 4, and $6 \mathrm{~mm}$ from the apex, and the sections were then observed under a stereomicroscope. The absence or presence of cracks was recorded.

Results No cracks were observed in the control group. There was presence of cracks at all the levels in all the experimental groups. There was a significant difference in crack formation when the groups were compared whereas this difference was not significant when the levels were compared $(p>0.05)$. In the SmartTrack group, there was crack in $73 \%$ samples whereas in HyFlex CM and ProTaper Next, the number of samples with cracks was $27 \%$ and $53 \%$, respectively. In the apical region, the number of samples that shows cracks was $29 \%$ whereas the number of cracks in the middle and coronal regions was $20 \%$.

Keywords

Conclusion Within the limitations of this study, root canal preparation with rotary

- crack nickel-titanium ( $\mathrm{Ni}$-Ti) instruments can cause crack formation in root canal dentin. The

- SmartTrack

- ProTaper next ProTaper Next and HyFlex instruments have a tendency to cause fewer dentinal cracks compared with the SmartTrack instruments.
\end{abstract}

\section{Introduction}

In endodontics, the root canal preparation aims at complete elimination of various microorganisms, clearing debris and shaping and enlarging the canal in a way that permits a proper seal. Cleaning and shaping of the root canal system lays down the foundation for successful endodontic therapy. This is achieved by the use of different types of endodontic instruments along with various types of irrigants.

received

October 29, 2018

accepted

October 30, 2018

published online

January 28, 2019
Conventional biomechanical preparation was accomplished by the use of stainless-steel hand instruments. As a part of progress in the treatment modalities, nickel-titanium (Ni-Ti) were introduced, which had greatly improved properties. In the past few years, modifications in rotary $\mathrm{Ni}-\mathrm{Ti}$ instruments have been done in the aspects of design and metallurgy. ${ }^{1}$ Superior performance of Ni-Ti instruments has been substantiated by a large number of studies and is an established fact now. Preparations done with
(C)2018 Bhojia Dental College and Hospital affiliated to Himachal Pradesh University
License terms

10.1055/s-0038-1676917 ISSN 2321-1482. 
rotary Ni-Ti instruments have fewer chances of procedural errors, improved cleanliness, and better canal shaping than those of conventional stainless-steel hand instruments. ${ }^{2-4}$

During root canal preparation, substantial amount of dentin is removed, which leads to weakening of the root. ${ }^{5}$ Resistance to fracture of an endodontically treated tooth is directly proportional to the amount of the remaining dentin. ${ }^{6}$ According to a study, force required to fracture an intact root is higher than that for a treated root. This proves that endodontically treated teeth are more susceptible to fracture as compared with intact teeth. ${ }^{7}$ Root canal preparations with rotary $\mathrm{Ni}$-Ti files generate stresses that are more on in internal surface than those on the external surface and are considerably higher in the apical third..$^{8}$ Therefore, the stress concentration in the apical area and gradual diminution of root structure have a major impact on crack propagation leading to vertical root fracture. ${ }^{9}$ Cracks cause deleterious and deteriorating effects on the health of the tooth. In a clinical condition, microorganisms can multiply in these cracks and can further establish biofilms on the root surface. ${ }^{10}$

In the background of this knowledge, it is but natural that significant amount of research would be directed toward the geometry and design modification of the instruments to minimize the potential for crack propagation. A large number of endodontic instruments have been developed and marketed in the past decade with promise of decreased stress concentration.

Recently, SmartTrack (Nikinc Dental, the Netherlands) files have been introduced. These files claim to use heat-treated $\mathrm{Ni}$-Ti that provides greater flexibility. These files can bend to extreme curves without breaking, thus reducing the risk of ledging, canal transportation, and instrument separation. ProTaper Next (Dentsply Maillefer, Chemin du Verger, Ballaigues, Switzerland) instruments use M-wire technology rendering increased flexibility. Its progressive taper and off-centered rectangular design enables it to have swaggering motion inside the root canal and to prevent screwing effect and taper lock. ${ }^{11}$ HyFlex CM (Cotene-Whaledent, Feldwiesenstrasse, Altstatten, Switzerland) rotary instruments uses controlled memory technology giving superior flexibility. It has symmetrical cross section with three cutting edges that improve the cutting efficiency. ${ }^{12}$

To the best of our knowledge, there has been no study that has tried to compare the probability of development and propagation of cracks on the inner surface of the root canal using the file systems mentioned previously: SmartTrack files, ProTaper Next files, and HyFlex CM files. This study was undertaken to detect the incidence of cracks in root dentin after root canal preparation using SmartTrack files, ProTaper Next files, and HyFlex CM files.

\section{Materials and Methods}

Sixty extracted single-rooted human mandibular premolars with one canal were used for the study. Single canal was confirmed with the help of a digital radiograph taken in both buccolingual and mesiodistal direction. Universal scaler was used to remove the calculus and soft tissue. A detailed examination of the samples was done under stereomicroscope $(25 \times)$ to rule out the presence of fracture lines and anatomical irregularities. Only straight canals and roots with curvature of maximum 10 degrees were included. The storage medium for the samples was distilled water. Straight-line access was ensured by removing $2 \mathrm{~mm}$ above the proximal cementoenamel junction (CEJ). This also helped in providing a stable reference point. After wrapping with single layer of aluminum foil, each root was embedded in acrylic resin. After the setting of acrylic resin, aluminum foil was removed and the space created was filled with light body addition silicon to mimic the periodontal ligament space. For intraoperative imaging, 2 to $3 \mathrm{~mm}$ of the root apex was left exposed. A size $10 \mathrm{~K}$-file (21 mm, Dentsply, Tulsa, Oklahoma, United States) was introduced into the samples until the tip of the file became visible through the root apex. The canals were then manually prepared with a size 10 stainless steel K-file using the balanced force technique until the file tip was seen at the apex. The samples were then randomly distributed into four groups of 15 samples each. For the control group, no preparation was done. For the experimental groups, a torque-controlled endodontic motor (X-Smart; Dentsply Maillefer) was used with the instrumentation regimen advised by the manufacturer of the file system.

\section{Group 1-Control $(n=15)$}

In this group no preparation was done with the rotary instruments.

\section{Group 2-SmartTrack $(n=15)$}

Group 2 SmartTrack files were used in the sequence NX, N1 (17/.06) till coronal two-thirds, N2 (17/.04), C1 (20/.06), C2 (25/.06), and C3 (30/.06) till working length at 300 to $500 \mathrm{rpm}$ (revolution per minute) with a gentle in-and-out motion.

\section{Group 3-ProTaper Next $(\boldsymbol{n}=\mathbf{1 5})$}

The root canals were prepared with the ProTaper Next system according to the manufacturer instructions. The instrumentation sequence will be SX, X1 (17/.04), X2 (25/.06), and X3 (30/.06). The SX file to be used at one-half of the WL, and the $\mathrm{X} 1, \mathrm{X} 2$, and $\mathrm{X} 3$ files were used at full WL.

\section{Group 4-HyFlex CM ( $n=15)$}

HyFlex files were used in a gentle in-and-out motion with a rotational speed of $500 \mathrm{rpm}$ and $250 \mathrm{~g} / \mathrm{cm}$ torque. The HyFlex files were used in the sequence of 25/0.08 (two-thirds of the working length), 20/.04, 25/.04, 20/0.06, and 30/0.04 (the full working length).

During the preparation procedure, $3 \%$ sodium hypochlorite $(\mathrm{NaOCl})$ was used for irrigation between successive instrumentation. Final rinse was done with 2-mL distilled water. Sections from all samples were procured by using a low-speed saw under water cooling. The sections were cut perpendicular to the long axis of the root at a distance of 2, 4, and $6 \mathrm{~mm}$ from the apex. Each section was digitally imaged at 30× magnification using a digital camera attached to a stereomicroscope. The sections were blindly examined for the presence of cracks. For analysis of the examination, 
two different categories were defined, that is, "no crack" and "crack." The section was to be analyzed as "no crack" if the root dentin did not show any craze lines or micro-cracks originating from the dentinal wall of the root canal. The section was classified under "crack" category if it showed evidence of any craze lines, micro-cracks, or fractures in the dentinal wall of root canals. Total 45 sections were examined in each group. -Fig. 1 shows the stereomicroscopic images of tooth slices. -Fig. 1A shows "no crack" and - Fig. 1B shows "crack."

\section{Results}

Results were expressed as the number and percentage of roots showing the defect in each group. The data were analyzed statistically using SPSS 16.0 (Armonk, NY). The comparisons were made using one- and two-way analysis of variance (ANOVA) test, followed by the post-hoc test.

No cracks were found in the control group. Cracks were present at all the levels in all the experimental groups. There was a significant difference in crack formation when the groups were compared whereas this difference was not significant when the levels were compared ( - Table $1 ; p \leq 0.05$ ).
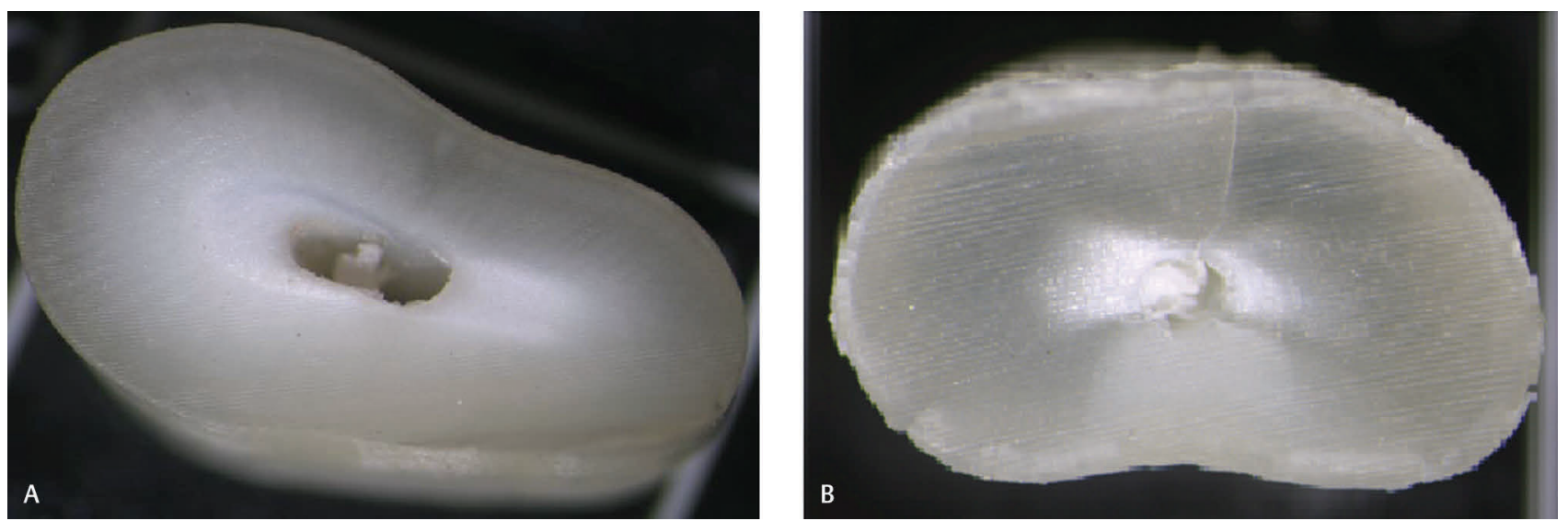

Fig. 1 (A) Stereomicroscopic image of tooth slice shows "no crack."

(B) Stereomicroscopic image of tooth slice shows "crack."

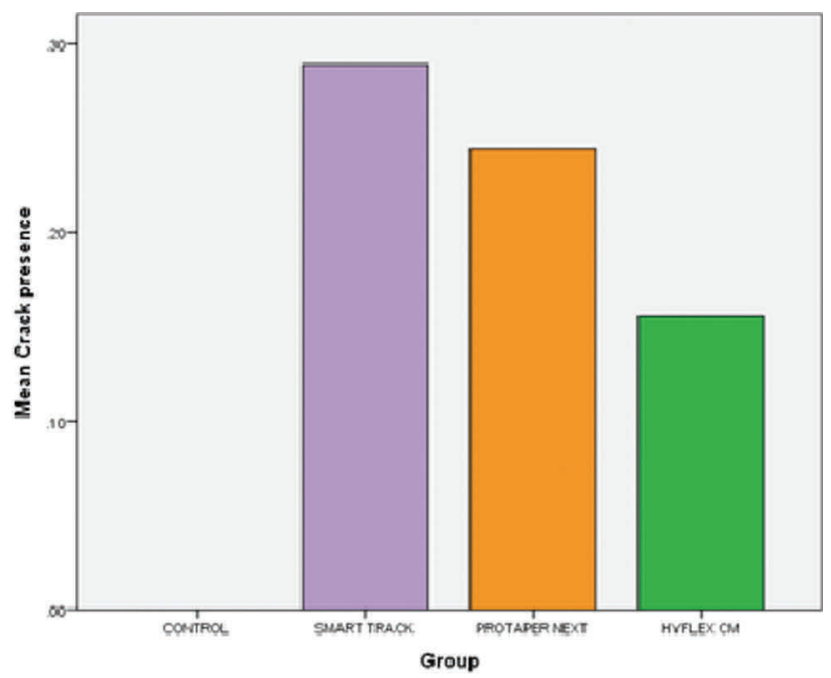

Fig. 2 Mean crack presence in all groups.
Table 1 Difference in crack formation in the groups and levels $(p \leq 0.05)$.

\begin{tabular}{|l|l|l|}
\hline Source & Sum of squares & Significance \\
\hline Levels & 0.178 & 0.515 \\
\hline Groups & 2.194 & 0.001 \\
\hline
\end{tabular}

Note: When the levels, that is, apical, middle and coronal thirds were compared, the differences in crack formation were not significant between them since $p>0.05$. When the groups were compared, the differences in crack formation were significant since $p<0.05$.

In the SmartTrack group, there was crack in 11 out of and ProTaper Next, the number of samples with cracks was 4 out of 15 and 8 out of 15 , that is, $27 \%$ and $53 \%$ samples, respectively.

There were differences in crack formation in the apical region as compared with middle or coronal regions. In the apical region, the number of samples that shows cracks was 13 out of 45 , that is, $29 \%$, whereas the number of cracks in the middle and coronal regions was 9 out of 45 samples, that is, $20 \%$. 15 samples, that is, in 73\% samples, whereas in HyFlex CM

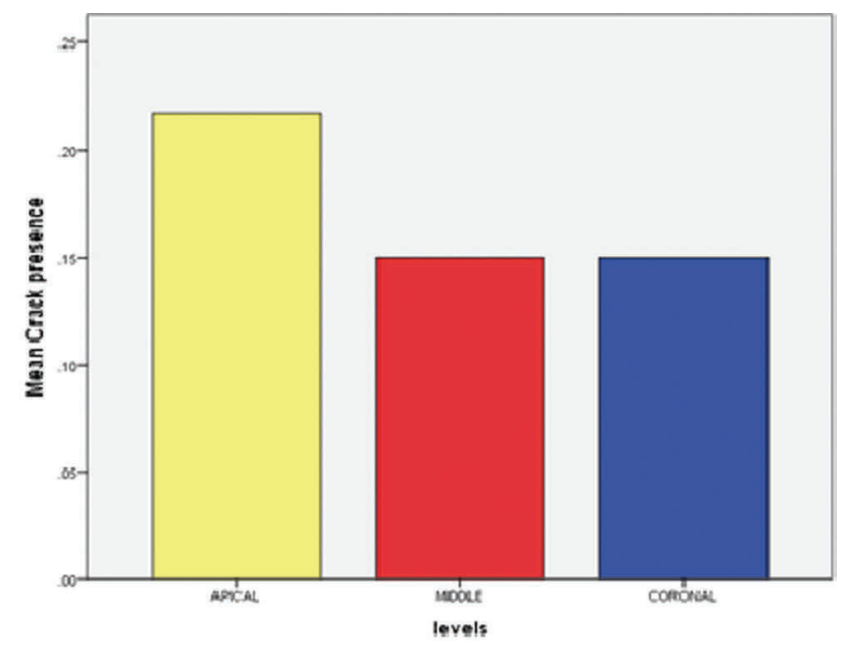

Fig. 3 Mean crack presence at the levels. 


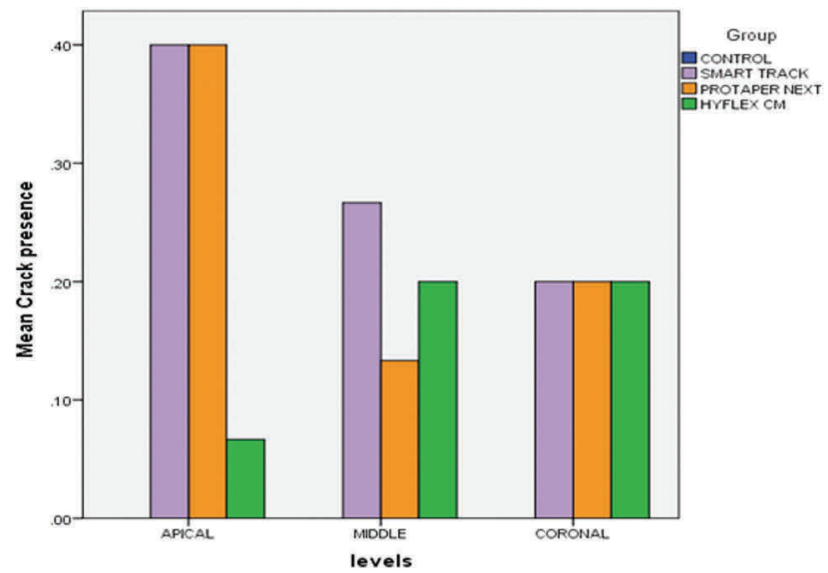

Fig. 4 Level-wise comparison of mean crack presence in the groups.

The mean crack presence in all the groups is graphically represented in -Fig. 2, whereas the mean crack presence in at the levels is graphically represented in -Fig. 3. The level-wise comparison of mean crack presence in the groups is graphically represented in - Fig. 4, whereas the group-wise comparison of mean crack presence at the levels is graphically represented in - Fig. $\mathbf{5}$.

\section{Discussion}

Distilled water is highly recommended for storage of teeth because of minimal dentinal changes during storage and was used for storing the samples in this study. ${ }^{13}$

There are several factors that contribute to crack formation during instrumentation. These factors are anatomy of the root canal: file used for preparation of glide path, taper of the rotary instrument, design and cross section of rotary instrument, number of files used, metallurgical design of file, hand or rotary files, and effective stiffness of file. ${ }^{14,15}$

During the biomechanical preparation, one of the frequently observed procedural errors is the deviation of apical foramen. This may add on to the initiation and propagation of cracks. This complication is mostly seen in curved root canals. In this investigation, only straight canals or roots with a curvature of maximum 10 degrees were included, and thus the confounding factor of apical curvature has been removed. ${ }^{15}$

Some studies, for example, Wilcox et al have made an attempt to imitate bone and periodontal ligament by covering the roots with aluminum foil and embedding them in acrylic resin. On the other hand, Lertchirakarn et al coated the roots with silicon paste. However, this setup may not entirely simulate the actual clinical situation due to different dynamics of force distribution. Soros et al (2008) concluded that rubber-based impression materials are ineffective to withstand masticatory forces as does the natural periodontal ligament. In this study, roots were surrounded by impression material and embedded in acrylic resin to mimic the bony socket and periodontal ligament. ${ }^{13}$

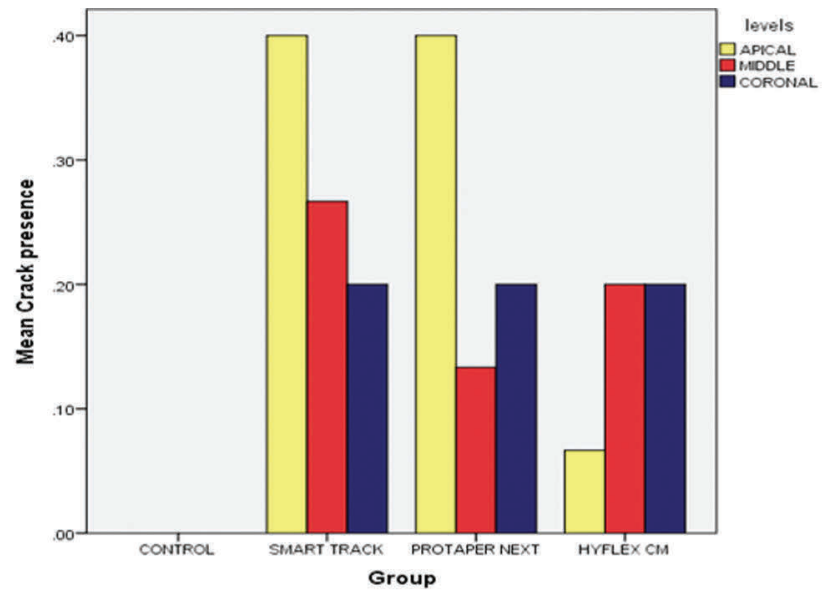

Fig. 5 Group-wise comparison of mean crack presence at the levels.

The root samples were left exposed in the apical 2- to $3-\mathrm{mm}$ region to record the intraoperative images. This simulates the clinical situation as an exposed root apex is commonly present in cases of chronic apical periodontitis or periapical cyst or granuloma. ${ }^{16}$

The metallurgical properties of the tested files are standardized as SmartTrack, ProTaper Next, and HyFlex CM are heat-treated files with different designs. In this study, the tip size has also been standardized to size $30 .{ }^{17}$

Wilcox et al hypothesized that root canal preparation generates stress inside the root canals, which overpowers the bond holding the dentin together leading to crack propagation. In this investigation, cracks are not seen in the unprepared samples proving that they were caused by the preparation itself. ${ }^{13}$

It is seen in several previous studies that if the glide path preparation is done up to size 10 , the crack incidence is high, whereas if the glide path is prepared up to size 15 or 20 , the crack incidence is low. Therefore, an inference can be withdrawn that the more the size of glide path preparation, the less is the incidence of crack. In this investigation, the glide path has been prepared to a size 10 in all the groups, and thus the confounding factor of glide path preparation has been taken care of. ${ }^{12}$

In this investigation, after root canal shaping with SmartTrack, ProTaper Next, and HyFlex CM rotary instruments, occurrences of the dentinal micro-cracks were $73.3 \%, 53.3 \%$, and $26.6 \%$, respectively. This is in conformity with a study by Capar et al, which showed cracks in $28 \%$ of roots prepared with HyFlex CM. ${ }^{12}$

The taper of the endodontic file may also contribute to the initiation and propagation of cracks as stated by Bier et al. The more the file taper, the more the stresses induced on the dentinal wall, the more the chances of crack formation. This is shown in this study as well because HyFlex CM has uniform taper whereas ProTaper Next has variable taper. Hence, the incidence of crack formation in ProTaper Next group is higher than that in HyFlex CM group. ${ }^{18}$

ProTaper Next system consists of four files, that is, SX, X1, $\mathrm{X} 2$, and X3, whereas SmartTrack system consists of six files, 
that is, NX, N1, N2, C1, C2, and C3. Therefore, ProTaper Next requires less number of instruments than Smart Track files that may have resulted in more cracks in SmartTrack files. This is in accordance with a study by Shemesh et al, which stated that the more the manipulation of the canal, the more the incidence of crack formation. Moreover, Wilcox et al stated that the manipulation of the root canal produces accumulative damage to the dentinal walls, which eventually leads to crack formation. This was confirmed in a study by Shemesh et al in which the crack propagation in retreatment cases was investigated. ${ }^{14,18,19}$

The sequence of instrumentation in HyFlex CM is 20/.04, 25/.04, 20/0.06, and 30/0.04. Smart Track follows the sequence of $17 / .04,20 / .06,25 / .06$, and 30/.06. Therefore, apparently the number of files with $6 \%$ taper was more in SmartTrack file system than that in HyFlex CM file system. This may have attributed to higher crack incidence in SmartTrack group.

Cracks were observed at all the levels whereas the crack formation is more in the apical region (28.88\%) than in middle (20\%) or coronal (20\%) regions. This can be attributed to an increased torque with the penetration depth of the instrument as being reported by Blum et al. ${ }^{20}$ it has been established that if the instrumentation is done till apical foramen or beyond the apical foramen, there is increased crack formation as stated by Liu et al. ${ }^{15}$

\section{Conclusion}

Within the limitations of this study, root canal preparation with rotary $\mathrm{Ni}-\mathrm{Ti}$ instruments can cause crack formation in root canal dentin. The ProTaper Next and HyFlex instruments have a tendency to cause fewer dentinal cracks compared with the SmartTrack instruments.

\section{Conflict of Interest}

None declared.

\section{References}

1 Young GR, Parashos P, Messer HH. The principles of techniques for cleaning root canals. Aust Dent J 2007;52(1, Suppl):S52-S63

2 Esposito PT, Cunningham CJ. A comparison of canal preparation with nickel-titanium and stainless steel instruments. J Endod 1995;21(4):173-176

3 Song YL, Bian Z, Fan B, Fan MW, Gutmann JL, Peng B. A comparison of instrument-centering ability within the root canal for three contemporary instrumentation techniques. Int Endod J 2004;37(4):265-271

4 Guelzow A, Stamm O, Martus P, Kielbassa AM. Comparative study of six rotary nickel-titanium systems and hand instrumentation for root canal preparation. Int Endod J 2005;38(10):743-752
5 Sathorn C, Palamara JE, Messer HH. A comparison of the effects of two canal preparation techniques on root fracture susceptibility and fracture pattern. J Endod 2005;31(4):283-287

6 Wilcox LR, Roskelley C, Sutton T. The relationship of root canal enlargement to finger-spreader induced vertical root fracture. J Endod 1997;23(8):533-534

7 Zandbiglari T, Davids $\mathrm{H}$, Schäfer E. Influence of instrument taper on the resistance to fracture of endodontically treated roots. Oral Surg Oral Med Oral Pathol Oral Radiol Endod 2006;101(1):126-131

8 Versluis A, Messer HH, Pintado MR. Changes in compaction stress distributions in roots resulting from canal preparation. Int Endod J 2006;39(12):931-939

9 Soros C, Zinelis S, Lambrianidis T, Palaghias G. Spreader load required for vertical root fracture during lateral compaction ex vivo: evaluation of periodontal simulation and fracture load information. Oral Surg Oral Med Oral Pathol Oral Radiol Endod 2008;106(2):e64-e70

10 Yoldas O, Yilmaz S, Atakan G, Kuden C, Kasan Z. Dentinal microcrack formation during root canal preparations by different NiTi rotary instruments and the self-adjusting file. J Endod 2012;38(2):232-235

11 Ruddle CJ. The ProTaper endodontic system: geometries, features, and guidelines for use. Dent Today 2001;20(10):60-67

12 Capar ID, Arslan H, Akcay M, Uysal B. Effects of ProTaper Universal, ProTaper Next, and HyFlex instruments on crack formation in dentin. J Endod 2014;40(9):1482-1484

13 Shemesh $\mathrm{H}$, Wesselink PR, Wu MK. Incidence of dentinal defects after root canal filling procedures. Int Endod J 2010;43(11):995-1000

14 Liu R, Hou BX, Wesselink PR, Wu MK, Shemesh H. The incidence of root microcracks caused by 3 different single-file systems versus the ProTaper system. J Endod 2013;39(8):1054-1056

15 Liu R, Kaiwar A, Shemesh H, Wesselink PR, Hou B, Wu MK. Incidence of apical root cracks and apical dentinal detachments after canal preparation with hand and rotary files at different instrumentation lengths. J Endod 2013;39(1):129-132

16 Adorno CG, Yoshioka T, Suda H. The effect of root preparation technique and instrumentation length on the development of apical root cracks. J Endod 2009;35(3):389-392

17 Ashwinkumar V, Krithikadatta J, Surendran S, Velmurugan N. Effect of reciprocating file motion on microcrack formation in root canals: an SEM study. Int Endod J 2014;47(7):622-627

18 Bier CA, Shemesh H, Tanomaru-Filho M, Wesselink PR, Wu MK The ability of different nickel-titanium rotary instruments to induce dentinal damage during canal preparation. J Endod 2009;35(2):236-238

19 Shemesh H, Roeleveld AC, Wesselink PR, Wu MK. Damage to root dentin during retreatment procedures. J Endod 2011;37(1):63-66

20 Blum JY, Machtou P, Esber S, Micallef JP. Analysis of forces developed during root canal preparation with the balanced force technique. Int Endod J 1997;30(6):386-396 